\title{
Urban Diversity in the Middle East: A Case Study of Tehran
}

\author{
Aynaz Lotfata (Corresponding author) \\ Middle East Technical University \\ Turkey \\ E-mail: a.lotfata@gmail.com
}

Received: June 18, 2015 Accepted: June 23, 2015 Published: June 24, 2015

doi:10.5296/ijch.v2i1.7887ＵRL: http://dx.doi.org/10.5296/ijch.v2i1.7887

Urban diversity can refer to many things, including diversification in socioeconomic status, ethnicities, education, activities and values. The advents of the eras of industrialization and globalization changed mixed-land uses and the integrated urban activities of the traditional urban structure in Middle Eastern cities. The nested land uses presented people's lifestyles and beliefs in traditional Iranian urban society. Not only did integrated urban space orient and encourage a diversity of users to meet and get to know each other, but also encouraged people to gain a strong sense of belonging to space and to collaborate in the transformation and re-structuring of urban space. Social collaboration leads to a socially constructed consciousness and capital reconfigures a social context. Accordingly, Iranian urban society has become spontaneously familiar with the concept of diversity, although the rapid growth of Iranian cities under industrialization changed the sustainable urban structures. Cities witnessed increasing diversity in the needs, values and beliefs of the individual, accordingly governments are faced with problems in an equal governing of socioeconomic sources of cities. These changes were accompanied by a political upheaval. The 1979 Iranian Revolution needed the centralized system of government to fix the economic recession of late Mohammad Reza Shah (second Pahlavi) era, to address the shortfalls in social infrastructure, and to tackle the high level of illiteracy, in that participative and open structures need social awareness. After the revolution, illiteracy stood at 49 percent in 1980, meaning 10 million people, and Tehran, the capital of Iran, ranked second in this regard among all cities. Accordingly, literacy drives were launched in the early 1980s, reaching a peak in the early 1990s after the Iran-Iraq war, and Tehran currently boasts a high rank of literary, standing at over 80 percent. Iranian society suffered social problems and rapid rural migrations to the largest cities for different reasons after the Islamic Revolution of 1979. Industrialization of the agricultural sector encouraged unemployed labors, who had no previous experience of urban life, settled in the Tehran city centers and illegal housing areas. During the Iran-Iraq 


\section{Macrothink

war, those who felt unsafe residing in border cities settled in Tehran, and in recent years, as a result of the isolated and independent economy of Iranian society, economic and social developments focused on the largest cities, encouraging people, particularly the young, to leave the smaller cities to find better jobs and greater social opportunities. Accordingly, the unplanned population explosion in Tehran permitted no participatory development, nor a participatory model of democracy, although Iranian society has been shaped traditionally by the interaction of linguistic and religious diversities.

Democracy is a context-sensitive phenomenon, and for Iran, based on its geo-political position in the Middle East and lack of security with its neighboring nations, its inconsistencies with international policies, its transnational process, and its 40 million people without economic participation, is a nation state that still has to be governed based on a hierarchical management model, and prepare a context with preliminary facilities and resources. That is to say, a participative structure that contributes to the central government in the governing of diversities occurs in a context with an over-qualified level of social welfare. Thereby, while Iranian urban society is founded traditionally on a democratic culture, the unplanned and unexpected demographical growth of cities has destroyed the human-based and integrated design of urban spaces over the last century. Despite the failures in the continuity of the traditional time-space experiences, as a common feature of diversity, the planning bureau launched cultural development programs in different zones of Tehran city, particularly in the city center, encouraging the co-existence of ethnicities (Christian, Muslim, Jewish and Zoroastrian).

\section{Copyright Disclaimer}

Copyright for this article is retained by the author(s), with first publication rights granted to the journal.

This is an open-access article distributed under the terms and conditions of the Creative Commons Attribution license (http://creativecommons.org/licenses/by/3.0/). 